\title{
Erratum to: The wettability and bonding performance of densified VTC beech (Fagus sylvatica L.) and Norway spruce (Picea abies (L.) Karst.) bonded with phenol-formaldehyde adhesive and liquefied wood
}

\author{
Aleš Ugovšek • Frederick A. Kamke • \\ Milan Sernek • Matjaž Pavlič • Andreja Kutnar
}

Published online: 21 February 2013

(C) Springer-Verlag Berlin Heidelberg 2013

Erratum to: Eur. J. Wood Prod.

DOI 10.1007/s00107-013-0669-4

The original version of this article unfortunately contained a mistake. The first author's given and family name were exchanged. The given name is Aleš, the family name is Ugovšek.

The online version of the original article can be found under doi:10.1007/s00107-013-0669-4.

\footnotetext{
A. Ugovšek · M. Sernek · M. Pavlič Department of Wood Science and Technology, Biotechnical Faculty, University of Ljubljana, Rožna dolina, C. VIII/34, 1000 Ljubljana, Slovenia

F. A. Kamke

Department of Wood Science and Engineering, Oregon State University, 119 Richardson Hall, Corvallis, OR, USA

\section{A. Kutnar $(\bowtie)$}

Andrej Marušič Institute, University of Primorska,

Muzejski trg 2, 6000 Koper, Slovenia

e-mail: andreja.kutnar@upr.si
A. Kutnar
ILTRA d.o.o., Celovška cesta 268, 1000 Ljubljana, Slovenia 